\title{
Adult Acute Myeloid Leukemia
}

National Cancer Institute

\section{Source}

National Cancer Institute. Adult Acute Myeloid Leukemia. NCI Thesaurus. Code C9154.

An acute myeloid leukemia occurring in adults. 